\title{
Resuscitation medicine: a dose or two for everyone
}

\author{
Venkataraman Anantharaman ${ }^{1,2,3,4}$, MBBS, FRCSEd
}

n $\mathrm{n}$ the course of our medical career, most of us will have encountered very sick and haemodynamically unstable patients, even some in cardiac arrest. Have we always done our best for these patients? Have we kept up with the literature and the latest guidelines on how to get the patient back to a reasonable state of survival (and yes, with good cerebral performance)?

Since graduation from medical school (which was a long time ago for some of us), many doctors have not undergone any structured or supervised training in the art of resuscitation. When I was a medical student, it was usually a case of 'see one, do one'. Therefore, not many of us appreciated that it was not enough to just give our cardiac arrest patients a few very rapid chest compressions and check their heart rhythms. Before the start of formal cardiopulmonary resuscitation (CPR) training in 1983, I had the opportunity to resuscitate patients alongside some very senior cardiologists and anaesthetists. Using the 'see one, do one' approach, I used to pump hard on the patient's chest wall, often not allowing full chest recoil, pause after every 10-20 chest compressions, and then check the carotid, femoral and radial pulses. For every cardiac arrest, we used to run a full sodium bicarbonate drip and give intravenous calcium chloride to our patients. In those days, there were no formal standards to guide us.

The year 1983 was a landmark year for resuscitation training in Singapore. Formal CPR training was introduced, ${ }^{(1)}$ and I was among the first few groups of doctors to be trained, initially as a provider and subsequently, as an instructor. Some aspects of how we have progressed are covered in this issue of the Singapore Medical Journal (SMJ). The SMJ must be complimented for faithfully publishing all the previous national guidelines on resuscitation produced by the National Resuscitation Council (NRC) in 2001, (2-4) $2006^{(5)}$ and 2011. ${ }^{(6-9)}$ The reader is advised to peruse these previous editions of the journal to better understand how the science has progressed in the country and how some issues ${ }^{(10,11)}$ were dealt with. The present themed issue on resuscitation gives us a good opportunity to review how far we have come over the last 34 years and what more we can do to improve the quality of resuscitation.

Resuscitation entails more than just guidelines, training centres and public training. The clinical practice of resuscitation, whether in-hospital or out-of-hospital, has taken on a seriousness that concerns quality of practice, speed of implementation and an increasing realisation that every one of our patients deserves only the best skill we can offer. However, it is also recognised that one often has to resuscitate collapsed patients under less-than-optimal conditions. Therefore, while the practice of CPR and other aspects of resuscitation is moving toward greater quality management, ${ }^{(12,13)}$ real-life limitations occasioned by adverse environmental and practice settings (e.g. while moving the patient, in an ambulance or in space-constrained settings), as well as human factors (such as rescuer fatigue and physical limitations), constrain the potential for benefit that can otherwise accrue. There is also a need to acknowledge that, sometimes, even with the best environment for resuscitation, including the most efficient standard of CPR, clinical outcomes may not turn out as desired. With the increasing expectations of the public, care providers are frequently being taken to task for these less-than-desired outcomes. ${ }^{(14)}$ The challenge is in establishing good communication practices between care providers and families to address these potentially explosive situations. Additionally, there is a need to improve the standards of resuscitation practice through skill upgrading, better use of devices and regular feedback, all of which are expected of the various medical disciplines.

When resuscitation training first began 34 years ago, most people who underwent the programme would have considered themselves well trained after attending just one session. Over the years, the understanding that skills and knowledge can depreciate has led to training certificates having a limited period of validity, as well as the requirement for refresher training as a form of selfrenewal and to keep abreast of the practice. Therefore, all public and most private sector hospitals in Singapore today recommend all healthcare workers with patient contact to be currently CPR certified and members of identified disciplines to be certified in other life support programmes, unless exempted for special reasons. Training standards have become more clearly specified and form a very important component of the accreditation process for training centres. Extensive literature on educational methodologies and pedagogy of various forms of life support training has also been published.

In addition, current-day guidelines on resuscitation are increasingly guided by research evidence. The volume of research on resuscitation practices has ballooned tremendously over the last five decades, with the availability of an international peerreviewed scientific journal and multiple annual conferences on resuscitation being conducted. Needless to say, research evidence has to be relevant to local practice. Therefore, while there is an International Liaison Committee on Resuscitation (ILCOR) that produces consensus documents on resuscitation science at five-yearly intervals, more and more countries have also set up national councils to guide the practice, teaching and research of this developing and critically important area of medicine. Singapore's resuscitation council (i.e. NRC) was formed in 1998. Since then, Singapore has played a leadership role in setting up

${ }^{1}$ National Resuscitation Council, ${ }^{2}$ Department of Emergency Medicine, Singapore General Hospital, ${ }^{3}$ National University of Singapore, ${ }^{4}$ Duke-NUS Medical School, Singapore Correspondence: Prof Venkataraman Anantharaman, Chairman, National Resuscitation Council and Senior Consultant, Department of Emergency Medicine, Singapore General Hospital, Outram Road, Singapore 169608. anantharaman@singhealth.com.sg 
the Resuscitation Council of Asia, and also actively participates in ILCOR deliberations. Each country's national council uses its access to international literature to decide what practices would be best for its own local environment. That is the way it should be. In addition, Singapore has developed resuscitation research teams in various public hospitals, which have often combined forces to better understand the status of resuscitation issues in the country and published a lot of this research not only in the SMJ, but also in other international peer-reviewed scientific journals. Singapore has also taken a leadership role within Asia in coordinating regional efforts in resuscitation research. Evidently, research has become an integral part of the practice of resuscitation.

This issue of the $S M$ J demonstrates the efforts and progress that have occurred in the field of resuscitation, in terms of its practice, teaching and research. It also spells out the 2016 National Guidelines on Resuscitation that were announced by the NRC in May 2016. Changes in the national guidelines have already been reflected in the appropriate revised provider manuals produced by the council. Resuscitation medicine, which encompasses clinical practice, teaching and research, has become accepted in many quarters of the medical world as a discipline within the profession. ${ }^{(15,16)}$ While Singapore may not need to designate resuscitation medicine as an official subspecialty, it is important to recognise the existence of this new and evolving branch of medicine. Efforts by local practitioners, teachers and researchers in the field of resuscitation medicine also need to be acknowledged and actively supported by the stakeholders in the country, principally the healthcare institutions, community organisations and those who have benefitted from the various resuscitation efforts. Eventually, most members of the public will, sooner or later, need a dose or two of resuscitation treatment. When that situation arises, they will want to be assured that the quality, type and dose of resuscitation delivered will be the best under the circumstances.

\section{REFERENCES}

1. Choo $\mathrm{MH}$, Tan $\mathrm{WC}$, Oon $\mathrm{CH}$, et al. Cardiopulmonary resuscitation at the Singapore General Hospital. Ann Acad Med Singapore 1984; 13:542-7.

2. Teo WS. Advanced cardiac life support (ACLS). Singapore MedJ 2001; Suppl 1:10-20.

3. Anantharaman V. Automated external defibrillation (AED). Singapore Med J 2001; Suppl 1:4-9.

4. Lim SH. Basic cardiac life support (BCLS). Singapore Med J 2001; Suppl 1:2-3.

5. Teo WS, Anantharaman V, Lim SH. Update on resuscitation 2006. Singapore Med J 2007; 48:100-5.

6. Lim SH. Basic Cardiac Life Support: 2011 Singapore guidelines. Singapore Med J 2011; 52:538-43.

7. Lee F. Defibrillation. Singapore Med J 2011; 52:544-7.

8. Anantharaman V, Gunasegaran K. Advanced Cardiac Life Support guidelines 2011. Singapore Med J 2011; 52:548-56.

9. Singapore National Resuscitation Council's Neonatal and Paediatric Resuscitation Workgroup, Chong NK. Newborn and paediatric resuscitation 2011 guidelines. Singapore Med J 2011; 52:560-72.

10. Anantharaman V. Developing resuscitation programs in the community: the tasks ahead for the National Resuscitation Council. Singapore Med J 2011; 52:634-41.

11. Anantharaman V. Implementation of National Resuscitation Guidelines 2006. Singapore Med J 2011; 52:533-7.

12. Ong EH. Improving the quality of CPR in the community. Singapore Med J 2011; 52:586-91.

13. Leong BS, Chua GS. Quality of resuscitation in hospitals. Singapore Med J 2011; 52:616-9.

14. Kuah BT. Medico-legal issues in cardiopulmonary resuscitation and defibrillation. Singapore Med J 2011; 52:642-3.

15. Safar P. Book review on "Life in the Balance: Emergency Medicine and the quest to reverse sudden death." N Engl J Med 1997; 337:206-7.

16. Chamberlain D, Cummins RO, Montgomery WH, Kloeck WG, Nadkarni VM. International collaboration in resuscitation medicine. Resuscitation 2005; 67:163-5. 